\title{
Aplikasi Augmented Reality Sebagai Media Promosi Untuk Pemodelan Halte Bus Berbasis Android
}

\author{
Rizki Azandika Erdiantama, Hafid Setyo Hadi, M.T
}

Politeknik Negeri Media Kreatif Jakarta,

Jl. Srengseng Sawah No.26, RT.11/RW.3, Lenteng Agung, Kec. Jagakarsa, Kota Jakarta Selatan, Daerah Khusus Ibukota Jakarta 12630

\begin{tabular}{|c|}
\hline INFORMASI ARTIKEL \\
\hline $\begin{array}{l}\text { Sejarah Artikel: } \\
\text { Diterima Redaksi: } 20 \text { April } 2021 \\
\text { Diterbitkan Online: } 31 \text { Juli } 2021\end{array}$ \\
\hline KATA KUNCI \\
\hline $\begin{array}{l}\text { Augmented Reality, Booklet, Halte bus, Media } \\
\text { Iklan }\end{array}$ \\
\hline KORESPONDENSI \\
\hline Email penulis 1 : rizkiazandikae@gmail.com \\
\hline E-mail penulis 2 : hafid@polimedia.ac.id \\
\hline
\end{tabular}

\section{PENDAHULUAN}

Promosi adalah salah satu faktor pembanding keberhasilan dari suatu kegiatan pemasaran. Pada hakikatnya promosi adalah bentuk dari komunikasi pemasaran. Komunikasi pemasaran merupakan kegiatan pemasaran yang berusaha untuk memberikan informasi secara luas, serta berusaha untuk mempengaruhi atau membujuk pasar sasaran atas perusahaan dan produknya agar bersedia menerima dan setia pada produk yang ditawarkan oleh suatu perusahaan (Maimunah, 2012). Promosi tidak hanya memperkenalkan produk kepada konsumen atau calon komsumen saja, akan tetapi harus di ikuti upaya untuk mempengaruhi serta membujuk agar konsumen atau calon konsumen tersebut menjadi senang dan kemudian membeli produk yang di tawarkan.
Banyak sekali bentuk penerapan media yang dapat digunakan untuk mempromosikan suatu produk. Faktor tersebut di dukung dengan perkembangan zaman yang semakin modern. Sehingga mendorong media promosi untuk menemukan bentuk penerapan media yang baru. Selain itu juga adanya tuntutan dari strategi promosi yang dikembangkan suatu perusahaan untuk mencapai target pencapaian demi kemajuan perusahaan tersebut. Beberapa jenis media yang sering digunakan oleh perusahaan adalah media elektronik, media cetak dan media iklan Out Of Home.

Media out of home dapat didefinisikan sebagai iklan yang menggunakan berbagai bentuk media yang menarik perhatian, bertujuan untuk menjangkau target market di luar rumah. Menurut Shimp Out Of Home advertising adalah iklan yang menyediakan informasi tentang produk atau jasa dan berada di sekitar kita (Terence A. Shimp, 2010). Media out of home juga dapat menjangkau sarana dan prasana publik seperti stasiun, bandara, pelabuhan terminal bis, halte, taman kota dan 
sebagainya. Media Out Of Home juga lebih efektif karena masyarakat secara tidak langsung dipaksa untuk melihat informasi tersebut.

Domade Maha Promosindo merupakan perusahaan yang bergerak dalam bidang jasa advertising / periklanan, event \& production house yang mengerti akan kebutuhan pelanggan dalam era globalisasi ini. Dengan pengalaman dan sumber daya manusia multi disiplin ilmu serta dilakukan dengan ketekunan. Domade dapat bekerja mulai dari konsep, desain, sampai dengan penerapannya. Domade memiliki komitmen yang kuat dalam mengembangkan iklan di bidang jasa. Domade menawarkan berbagai opsional penerapan media untuk kebutuhan klien dalam bidang periklanan. Diantaranya billboard, lightbox, aktivasi produk, videotron, umbul - umbul dan sebagainya. (Domade Maha Promosindo, 2013).

Berdasarkan yang diutarakan oleh bapak Rohani Aji (Jati, 2020). Domade memfokuskan terjun kedalam dunia media branding Out Of Home ( $\mathrm{OOH}$ ) karena dari 2018 - 2019 mereka sudah berhasil memasarkan beberapa produk tersebut. Selain itu Domade juga ingin menambah akses media iklan mereka dalam bidang sarana dan prasarana. Karena beberapa klien mereka beranggapan bahwa mereka membutuhkan media yang baru untuk dapat menarik konsumen bagi brand mereka. Melihat dari sisi ini, Domade mulai merambat media iklan mereka ke dalam fasilitas umum. Halte menjadi salah satu sasaran utama Domade dalam memasarkan suatu brand. Karena halte dianggap memiliki engagement yang berbeda dari media iklan lainnya. Dalam hal promosi, Domade masih menggunakan media digital seperti proposal proyek ( Rate Card) dalam bentuk format power point yang disebarkan melalui $e$-mail. Dan juga media cetak seperti booklet yang akan ditunjukan kepada calon klien pada saat meeting. Domade menggunakan gambar dua dimensi dan teks untuk menjelaskan setiap produk yang mereka tawarkan. Kegiatan promosi seperti ini memiliki kelemahan dalam memberikan sebuah informasi produk kepada konsumen karena mengandalkan teks dan gambar dua dimensi tanpa adanya bentuk visualisasi. Untuk itu PT. Domade Maha Promosindo memerlukan media / sarana dalam mempromosikan produk mereka.

Augmented Reality adalah sebuah teknologi yang mengkombinasikan benda virtual dua dimensi atau tiga dimensi ke dalam sebuah objek nyata tiga dimensi lalu memproyeksikan benda virtual tersebut secara langsung kedunia nyata. Teknologi Augmented Reality tidak seperti realitas virtual yang sepenuhnya menggantikan kenyataan, namun teknologi ini hanya bisa menambahkan atau melengkapi kenyataan tersebut.

Dengan melihat latar belakang dan permasalahan tersebut, maka tugas akhir ini dibuat untuk membantu pihak Domade Maha Promosindo dalam membuat suatu inovasi bidang promosi melalui teknologi Augmented Reality. Dengan membuat objek $3 D$ model halte bus yang dilengkapi dengan media iklan muncul melalui Marker. Pembuatan aplikasi ini dilakukan untuk mempermudah calon klien dalam mengetahui bentuk asli dari rancangan model halte prototype yang awalnya hanya dapat dilihat dalam bentuk dua dimensi. Namun dengan adanya teknologi Augmented Reality calon klien bisa lebih memahami dan lebih yakin dengan jasa yang ditawarkan oleh Domade Maha Promosindo.

\section{TINJAUAN PUSTAKA}

\subsection{Augmented Reality}

Augmented Reality adalah teknologi yang menggabungkan benda maya dua dimensi dan ataupun tiga dimensi ke dalam sebuah lingkungan nyata tiga dimensi lalu memproyeksikan benda-benda maya tersebut dalam waktu nyata. Tidak seperti realitas maya yang sepenuhnya menggantikan kenyataan, namun Augmented Reality hanya menambahkan atau melengkapi kenyataan (Sutrisno Adam, 2014).

Augmented Reality merupakan sebuah cara lain dalam memandang dunia nyata secara langsung maupun menggunakan kamera yang membuat sebuah visual di dalam dunia nyata, dan "menambah" objek yang dihasilkan komputer seperti grafis, audio, dan video. Augmented Reality memiliki perbedaan dengan Virtual Reality dalam penambahan objeknya, Augmented Reality menambahkan objek ke dalam dunia nyata atau pemandangan yang ada dibanding membuat goresan suatu hal baru. Salah satu hal terbesar yang ada pada Augmented Reality adalah kemampuannya dalam menempatkan sebuah objek maya kedalam 3 Dimensional, dan ruangan dunia nyata (Mealy, 2018).

Dilansir dalam tugas akhir Rama Andhika Yoga (Yoga, 2019), seorang pakar Azuma (Ronald, 1997) mendefinisikan Augmented Reality sebagai penggabungan benda-benda nyata dan maya di lingkungan nyata, berjalan secara interaktif dalam waktu nyata (realtime), dan terdapat integrasi antar benda dalam tiga dimensi, yaitu benda maya terintegrasi dalam dunia nyata. Penggabungan benda nyata dan maya dimungkinkan dengan teknologi tampilan yang sesuai interaktivitas dimungkinkan melalui perangkat-perangkat input tertentu. Bidang-bidang yang menerapkan teknologi Augmented Reality adalah:

a. Bidang pemasaran digunakan untuk mempromosikan barang atau jasa dengan brosur virtual yang memberikan informasi lengkap secara tiga dimensi sehingga pelanggan dapat mengetahui secara jelas mengenai barang atau jasa yang ditawarkan.

b. Bidang pendidikan digunakan untuk proses belajar mengajar yang memberikan efek-efek yang dapat mengubah gambar animasi tentang cuaca tersebut.

c. Bidang desain teknologi digunakan untuk menampilkan hasil desain mereka secara nyata terhadap klien.

\subsubsection{Metode Augmented Reality}

Marker-based Augmented Reality (AR) adalah gambar yang dapat dideteksi oleh kamera dan digunakan dengan perangkat lunak sebagai lokasi untuk aset virtual yang ditempatkan dalam sebuah penanda. Sebagian besar berwarna hitam dan putih, meskipun warna dapat digunakan selama karena kontras di antara mereka dapat dikenali dengan baik oleh sebuah kamera. Penanda Augmented Reality sederhana dapat terdiri dari satu atau lebih banyak bentuk dasar yang terbuat dari kotak hitam dengan warna latar belakang putih. Marker yang lebih rumit dapat dibuat menggunakan gambar sederhana yang masih dibaca dengan benar oleh kamera, dan kode-kode ini bahkan dapat berbentuk tato.

Kamera yang di kombinasikan dengan AR digunakan untuk mendeteksi penanda Augmented Reality sebagai lokasi untuk objek virtual atau maya. Hasilnya adalah gambar dapat dilihat 
secara langsung di layar dan aset digital dapat diletakkan ke dalam suatu tempat di lokasi tersebut. Keterbatasan pada beberapa jenis Marker-based Augmented Reality bisa berdasarkan pada perangkat lunak yang mengenalinya. Sementara Marker membutuhkan pengoreksi kesalahan agar mereka bisa memasukan jangkauan yang luas pada beberapa gambar. Beberapa jenis Marker Augmented Reality yang paling sederhana adalah gambar hitam dan putih yang terdiri dari barcode dalam bentuk dua dimensi (2D).

\subsubsection{Marker-less}

Sistem Marker-less pada Augmented Reality menggunakan kombinasi dari beberapa alat elektronik seperti: accelerometer, kompas, data lokasi (GPS), 3D object tracking, dan motion tracking untuk menentukan posisi pada dunia nyata, dimana sistem ini akan mengarahkan poros mana dari suatu alat yang beroperasi. Data lokasi ini kemudian juga bisa dibandingkan dengan database yang menentukan apa yang dilihat perangkat, dan dengan memungkinkan komputer untuk menampilkan grafis pada layar. Teknologi ini menciptakan 'Mobile Augmented Reality', dengan menggunakan perangkat teknologi seperti smartphone dan tablets.

\subsection{Promosi}

Promosi berasal dari kata promote dalam bahasa Inggris yang diartikan sebagai mengembangkan atau meningkatkan. Promosi merupakan salah satu komponen dari bauran pemasaran (marketing mix). Promosi dapat juga diartikan sebagai upaya untuk memberitahukan atau menawarkan produk atau jasa pada dengan tujuan menarik calon konsumen untuk membeli atau mengkonsumsinya. Dengan adanya promosi produsen atau distributor mengharapkan kenaikannya angka penjualan. Fungsi promosi dalam bauran pemasaran adalah untuk mencapai berbagai tujuan komunikasi dengan konsumen.

Kotler (Kotler, 2000) menyatakan bahwa promosi adalah bagian dan proses strategi pemasaran sebagai cara untuk berkomunikasi dengan pasar dengan menggunakan komposisi bauran promosi "promotional mix". Aktivitas promosi merupakan usaha pemasaran yang memberikan berbagai upaya intensif jangka pendek untuk mendorong keinginan mencoba atau membeli suatu produk atau jasa. Seluruh kegiatan promosi bertujuan untuk mempengaruhi perilaku pembelian, tetapi tujuan promosi yang utama adalah memberitahukan, membujuk dan mengingatkan.

Menurut Terence (Terence A. Shimp, 2010) promosi memiliki lima fungsi yang sangat penting bagi perusahaan/lembaga. Berikut adalah kelima fungsi dari kegiatan promosi:

1. Informing (Memberikan informasi)

Promosi merupakan sarana untuk mengenalkan produk kepada para konsumen. Promosi membuat konsumen sadar akan produk-produk baru, mendidik mereka tentang berbagai fitur dan manfaat merek, serta memfasilitasi penciptaan citra sebuah perusahaan yang menghasilkan produk atau jasa.

2. Persuading (Membujuk)
Media promosi atau iklan yang baik akan mampu mempersuasi pelanggan untuk mencoba produk dan jasa yang ditawarkan. Terkadang persuasi berbentuk mempengaruhi permintaan primer, yakni menciptakan permintaan bagi keseluruhan kategori produk.

3. Reminding (Mengingatkan )

Iklan menjaga agar merek perusahaan tetap segar dalam ingatan para konsumen. Saat kebutuhan muncul, yang berhubungan dengan produk dan jasa yang diiklankan, dampak promosi di masa lalu memungkinkan merek pengiklan hadir di benak konsumen.

4. Adding value ( Menambah nilai )

Terdapat tiga cara mendasar dimana perusahaan bisa memberi nilai tambah bagi penawaran-penawaran mereka, inovasi, penyempurnaan kualitas, atau mengubah persepsi konsumen. Ketiga komponen nilai tambah tersebut benarbenar independen.

5. Assisting (Mendampingi upaya - upaya lain dari perusahaan) Periklanan merupakan salah satu alat promosi. Promosi membantu perwakilan penjualan. Iklan mengawasi proses penjualan produk-produk perusahaan dan memberikan pendahuluan yang bernilai bagi wiraniaga sebelum melakukan kontak personal dengan para pelanggan yang prospektif

\subsection{Media iklan Out Of Home}

Media iklan Out Of Home $(\mathrm{OOH})$ diartikan sebagai iklan yang menggunakan berbagai bentuk media yang berada diluar. Tujuannya adalah menjangkau target market yang sedang berada diluar rumah. Menurut Terence (Terence A. Shimp, 2010) adalah iklan yang menyediakan informasi mengenai produk atau jasa dan berada di berbagai tempat.

Menurut Jefkins (Jefkins, 1997) mengatakan bahwa iklan media luar ruang adalah bentuk iklan yang paling tua. Pada saat itu dinding adalah tempat utama menulis pesan untuk masyarakat luas pada masa Yunani dan Romawi. Selanjutnya media luar ruang berkaitan dengan bangunan atau aktivitas yang ada dalam suatu bangunan. Media luar ruang tersebut menandakan atau menginformasikan mengenai kuil, makam, istana dan biasanya bangunan yang dianggap penting. Pada waktu revolusi industri di Inggris menimbulkan dampak berkembangnya sektor industri, komersial, jasa dan munculnya kota-kota baru, kepentingan ekonomi serta semakin luasnya kota mendorong perkembangan pemakaian dan pemasangan media luar ruang yang bersifat komersial.

Media luar ruang berfungsi sebagai media untuk menyampaikan pesan yang meraih peranan penting dalam proses komunikasi. Tanpa adanya media, pesan tidak akan sampai pada audiens yang ditargetkan. Pemilihan media yang tepat dapat menentukan apakah pesan yang disampaikan ke audiens yang ditargetkan akan sampai atau tidak. (Sutisna, 2003).

\subsection{Android Operating System}

Android adalah sebuah sistem operasi untuk perangkat ponsel yang merupakan versi modifikasi dari Linux. Awal mulanya dikembangkan oleh startup dengan nama yang sama seperti sistem operasinya yaitu Android Inc. Pada tahun 2005, agar bisa memasuki dunia pasar ponsel, maka Google membeli 
Android Inc dan mengambil alih hasil pengembangan beserta tim pengembangnya.

Google menginginkan Android OS dapat digunakan banyak pengguna secara gratis dan dapat dikelola terbuka, sehingga Android merilis hampir seluruh kode di bawah lisensi open source Apcahe. Maka siapapun yang ingin menggunakan Android juga bisa mengunduh keseluruhan source code Android (DiMarzio, 2017).

Android selalu mengembangkan sistem operasinya sehingga telah tercipta banyak versi dengan keunggulannya. Berikut adalah perkembangan versi Android dimulai dari awal tercipta sampai saat ini (Raphael, 2020).

\section{KONSEP PERANCANGAN}

\subsection{Gambaran Umum Domade Maha Promosindo}

PT. Domade Maha Promosindo didirikan pada tahun 2013, bergerak di bidang jasa periklanan / advertising, event \& production house yang mengerti akan kebutuhan pelanggan dalam era globalisasi ini. Dengan pengalaman dan sumber daya manusia multi disiplin ilmu serta dilakukan dengan ketekunan. Kami dapat bekerja mulai dari konsep, desain, sampai dengan penerapan.

\subsection{Sistem Yang Sedang Berjalan}

Sistem media promosi dalam bentuk proposal pemodelan halte yang dimiliki oleh PT. Domade Maha Promosindo masih dibuat hanya dalam bentuk informasi dengan elemen teks dan gambar 2D.

Media promosi yang digunakan Domade dalam memasarkan produk mereka adalah media digital dan media cetak. Dalam bidang media digital Domade membuat proposal proyek (Rate Card) dengan format powerpoint yang nantinya akan dibagikan ke klien mereka melalui E-mail perusahaan. Media promosi yang digunakan Domade dalam memasarkan produk mereka adalah media digital dan media cetak. Dalam bidang media digital Domade membuat proposal proyek (Rate Card) dengan format powerpoint yang nantinya akan dibagikan ke klien mereka melalui E-mail perusahaan. Sedangkan media cetak yang mereka gunakan adalah booklet. Booklet tersebut akan diperlihatkan kepada klien pada saat meeting dan dijelaskan secara langsung. Di dalam booklet hanya berisi tulisan dan gambar 2D saja. Berikut gambaran dan bentuk proposal pemodelan halte yang sudah pernah dibuat adalah sebagai berikut:

\subsection{Sistem Media Promosi Yang Akan Dikembangkan}

Gambar dibawah menjelaskan alur proses yang dilakukan seorang sales dengan adanya teknologi Augmented Reality. Pada saat sales melakukan meeting dengan klien mereka membawa Smartphone yang telah terpasang aplikasi Augmented Reality dan membawa media cetak booklet. Didalam booklet telah dilengkapi dengan Marker model halte bus dan juga penjelasan tentang fitur seputar halte tersebut. Sehingga pada saat meeting berlangsung sales hanya perlu memindai Marker agar klien dapat lebih memahami model halte bus yang ditawarkan.

\subsection{Perancangan Sistem}

Use Case adalah rangkaian/uraian pengguna yang saling terkait dan membentuk sistem secara teratur yang diawasi oleh sebuah aktor. Use case digunakan untuk membentuk apa yang dilakukan oleh pengguna yang direalisasikan oleh sebuah sistem.

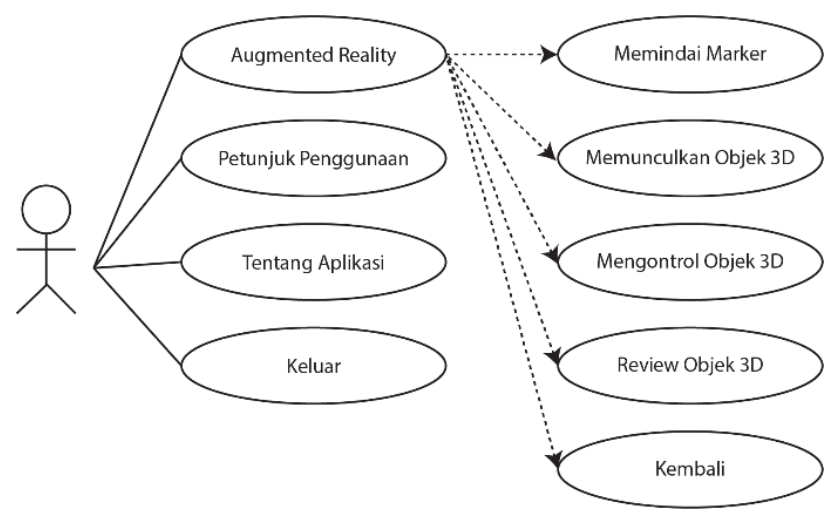

Gambar 3.1. Use Case Diagram

Activity Diagram ini menggambarkan aktivitas ketika aktor menekan AR Kamera untuk memindai Marker pada booklet dengan AR Camera, kemudian Marker akan terdeteksi hingga muncul objek 3D.

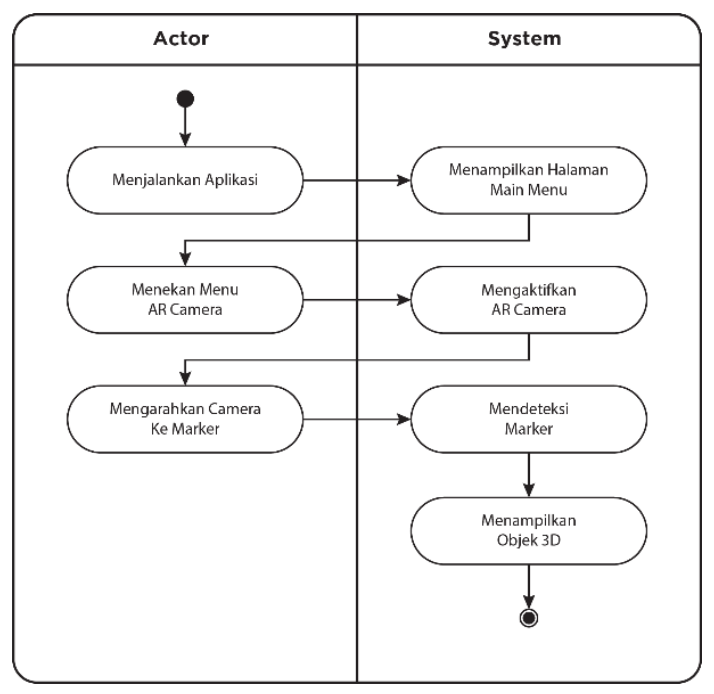

Gambar 3.2. Activity Diagram

Class diagram mendeskripsikan jenis-jenis objek dalam sistem dan berbagai macam hubungan statis yang terjadi. Selain itu, class diagram juga menunjukan properti dan operasi sebuah class dan batasan yang terdapat dalam hubungan dengan objek. Class diagram merupakan alat yang tergolong baik dalam perancangan perangkat lunak. 


\subsection{Pengujian Sistem}

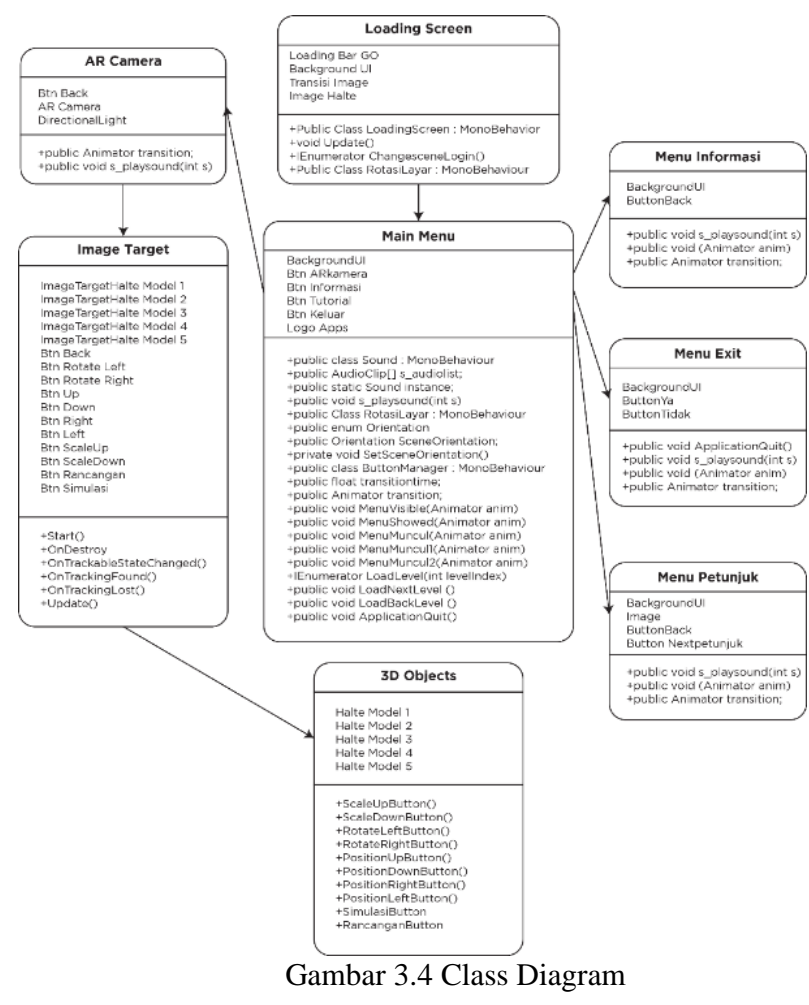

\section{HASIL DAN PEMBAHASAN}

\subsection{Implementasi Sistem}

Sebelumnya, penulis sudah membuat rancangan karya. Pada poin ini penulis akan menjabarkan hasil implementasi setelah dibuat kedalam bentuk karya.

Berikut tampilan halaman menu utama saat aplikasi Augmented Reality Pemodelan Halte Bus berjalan, terdapat pilihan menu: AR Kamera, Petunjuk, Informasi, dan Keluar.

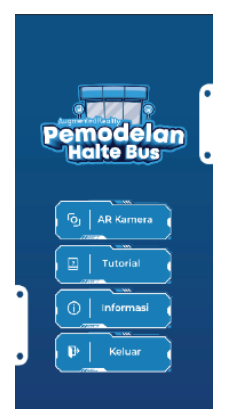

Gambar 4.1 Tampilan Halaman Menu Utama

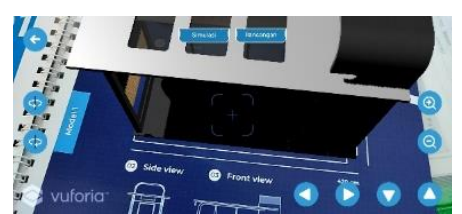

Gambar 4.2 Tampilan Halaman AR Kamera
Dalam pengujian aplikasi ini, penulis menggunakan perangkat smartphone Android dengan versi OS dan spesifikasi yang berbeda. Berikut hasil pengujian sistem yang penulis rangkum ke dalam bentuk tabel

Tabel 4.1 Pengujian Sistem Aplikasi

\begin{tabular}{|c|c|c|c|c|}
\hline \multirow[b]{2}{*}{ Skenario } & \multicolumn{4}{|c|}{ Spesifikasi Perangkat } \\
\hline & $\begin{array}{c}\text { Perangkat } \\
1\end{array}$ & $\begin{array}{c}\text { Perangkat } \\
2\end{array}$ & $\begin{array}{c}\text { Perangkat } \\
3\end{array}$ & $\begin{array}{c}\text { Perangkat } \\
4\end{array}$ \\
\hline $\begin{array}{l}\text { Loading } \\
\text { Awal }\end{array}$ & (o) & 9 & $\begin{array}{l}0 \\
\therefore . . .\end{array}$ & [0] \\
\hline $\begin{array}{c}\text { Menampilkan } \\
\text { Main Menu }\end{array}$ & & & 8 & \\
\hline $\begin{array}{c}\text { Menampilkan } \\
\text { UI Info }\end{array}$ & & & $=$ & \\
\hline $\begin{array}{c}\text { Menampilkan } \\
\text { UI Tutorial }\end{array}$ & & 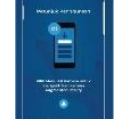 & $\underline{\underline{E}}$ & 吾 \\
\hline $\begin{array}{c}\text { Menampilkan } \\
\text { UI Keluar } \\
\text { Aplikasi }\end{array}$ & 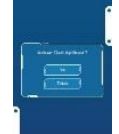 & 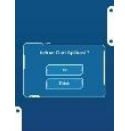 & $\therefore$ & \\
\hline
\end{tabular}

Tabel 4. 2. Pengujian Kamera berdasarkan Sudut Kemiringan

\begin{tabular}{|c|c|c|l|l|}
\hline $\begin{array}{c}\text { Sudut } \\
\text { Kemiringan }\end{array}$ & \multicolumn{4}{|c|}{ Spesifikasi Perangkat } \\
\hline 90 & $\begin{array}{c}\text { Perangkat } \\
1\end{array}$ & $\begin{array}{c}\text { Perangkat } \\
2\end{array}$ & $\begin{array}{c}\text { Perangkat } \\
3\end{array}$ & $\begin{array}{c}\text { Perangkat } \\
4\end{array}$ \\
\hline 60 & Terlihat & Terlihat & Terlihat & Terlihat \\
\hline 45 & Terlihat & Terlihat & Terlihat & Terlihat \\
\hline 30 & Terlihat & Terlihat & Terlihat & Terlihat \\
\hline 0 & Terlihat & Terlihat & Terlihat & Terlihat \\
\hline
\end{tabular}

Dalam pengujian aplikasi ini, penulis menguji kinerja kamera dengan berbagai jarak dengan target Marker. Berikut hasil pengujian yang penulis rangkum ke dalam bentuk tabel: 
Tabel 4. 3. Pengujian Kamera Berdasarkan Jarak

\begin{tabular}{|c|l|l|l|l|}
\hline \multirow{2}{*}{$\begin{array}{c}\text { Jarak Marker } \\
(\mathrm{cm})\end{array}$} & \multicolumn{4}{|c|}{ Spesifikasi Perangkat } \\
\cline { 2 - 5 } & $\begin{array}{c}\text { Perangkat } \\
1\end{array}$ & $\begin{array}{c}\text { Perangkat } \\
2\end{array}$ & $\begin{array}{c}\text { Perangkat } \\
3\end{array}$ & $\begin{array}{c}\text { Perangkat } \\
4\end{array}$ \\
\hline 50 & Terlihat & Terlihat & Terlihat & Terlihat \\
\hline 40 & Terlihat & Terlihat & Terlihat & Terlihat \\
\hline 30 & Terlihat & Terlihat & Terlihat & Terlihat \\
\hline 10 & Terlihat & Terlihat & Terlihat & Terlihat \\
\hline 5 & Tidak & Tidak & Tidak & Tidak \\
Terlihat & Terlihat & Terlihat \\
\hline
\end{tabular}

Dalam pengujian aplikasi ini, penulis menguji kinerja kamera dengan berbagai keadaan cahaya. Berikut hasil pengujian yang penulis rangkum ke dalam bentuk tabel:

Tabel 4. 4. Pengujian Kamera berdasarkan Keadaan Cahaya

\begin{tabular}{|c|c|c|c|c|}
\hline \multirow{2}{*}{$\begin{array}{c}\text { Keadaan } \\
\text { Cahaya } \\
\text { Sangat } \\
\text { Terang }\end{array}$} & \multicolumn{4}{|c|}{ Spesifikasi Perangkat } \\
\hline & $\begin{array}{c}\text { Perangkat } \\
1\end{array}$ & $\begin{array}{c}\text { Perangkat } \\
2\end{array}$ & $\begin{array}{c}\text { Perangkat } \\
3\end{array}$ & $\begin{array}{c}\text { Perangkat } \\
4\end{array}$ \\
\hline Terang & Terlihat & Terlihat & Terlihat & Terlihat \\
\hline Redup & Terlihat & Terlihat & Terlihat & Terlihat \\
\hline Gelap & $\begin{array}{l}\text { Tidak } \\
\text { Terlihat }\end{array}$ & $\begin{array}{l}\text { Tidak } \\
\text { Terlihat }\end{array}$ & $\begin{array}{l}\text { Tidak } \\
\text { Terlihat }\end{array}$ & $\begin{array}{l}\text { Tidak } \\
\text { Terlihat }\end{array}$ \\
\hline
\end{tabular}

Berdasarkan hasil pengujian aplikasi yang dilakukan pada empat perangkat yang berbeda dengan ketentuan jarak, sudut kemiringan, dan cahaya, maka dapat disimpulkan:

1. Handphone dengan minimal spesifikasi untuk berjalannya aplikasi berada pada perangkat ketiga yaitu menggunakan smartphone Samsung Galaxy J5 dengan spesifikasi RAM 2GB, sistem operasi Android Marshmallow dan kamera belakang 13MP, namun untuk hasil yang terbaik disarankan untuk menggunakan smartphone dengan spesifikasi RAM $3 \mathrm{~GB}$.

2. Agar target Marker terbaca dengan jelas arah kamera lebih baik diarahkan antara 30 - 90 derajat dengan cahaya yang terang serta untuk jarak yang terbaik adalah minimal $10-30 \mathrm{~cm}$.

3. Aplikasi sudah responsive sehingga dapat dijalankan kedalam smartphone yang memiliki variasi selain ukuran 1280 x 720 px.

\section{KESIMPULAN DAN SARAN}

Pada pembuatan aplikasi Augmented Reality sebagai media promosi untuk pemodelan halte bus, terdapat beberapa kesimpulan yang penulis dapat. Berikut kesimpulan dari pembuatan Karya Tugas Akhir ini:

1. Aplikasi Augmented Reality ini dinyatakan baik secara sistem maupun visual bagi Domade Maha Promosindo, dan juga memiliki tingkat efektifitas yang tinggi dalam mempromosikan produk / jasa yang ditawarkan. Serta dapat bisa lebih meyakinkan klien mereka dan juga User Interface aplikasi ini dapat dipahami dengan mudah.

2. Aplikasi ini telah mencapai tujuan yang diharapkan.
3. Pengenalan Marker terbaik saat melakukan pemindaian terdapat pada jarak 30 sampai $50 \mathrm{~cm}$ dengan sudut $45^{\circ}$ sampai $90^{\circ}$ dan cahaya yang terang.

\section{DAFTAR PUSTAKA}

[1] L. S. N. L. Maimunah, "MEDIA COMPANY PROFILE SEBAGAI SARANA PENUNJANG INFORMASI DAN PROMOSI," pp. 281 - 301, 2012.

[2] J. C. A. Terence A. Shimp, Advertising, Promotion, and other aspects of Integrated Marketing Communications, Ninth Edition, Mason USA: South-Western, 2010.

[3] Domade Maha Promosindo, Company Profile, Jakarta: Domade Maha Promosido, 2013.

[4] R. A. P. Jati, Interviewee, Target Media Branding Domade 2020. [Wawancara]. 18 February 2020.

[5] A. S. M. L. S. M. J. R. R. S. M. Sutrisno Adam, "Implementasi Teknologi Augmented Reality pada Agen Penjualan Rumah," E-journal Teknik Elektro dan Komputer, pp. 19-25, 2014.

[6] P. Mealy, Virtual and Augmented Reality For Dummies, Hoboken, New Jersey: Jhon Wiley \& Son Inc, 2018.

[7] R. A. Yoga, Pembuatan Aplikasi Augmented Reality Sebagai Media Informasi Mengenai Smart Branding Pada Smart City Berbasis Android, Jakarta: Politeknik Negeri Media Kreatif Jakarta, 2019.

[8] T. Ronald, "A Survey of Augmented Reality," Hughes Research Laboratories, pp. 355 - 385, August 1997.

[9] P. Kotler, Manajemen pemasaran: analisis, perencanaan, implementasi dan pengendalian, Jakarta: Salemba Empat, 2000.

[10] F. Jefkins, Advertising, Edition 3, T. H. Munandar, Penyunt., Jakarta: Erlangga, 1997.

[11] Sutisna, "Perilaku Konsumen dan Komunikasi Pemasaran,” Jurnal Komunikasi, 2003.

[12] S. Nurmasari, "Hubungan Media Ruang Luar ( Menggunakan Pencahayaan Buatan ) Dengan Kualitas Visual Koridor di Malam Hari Menurut Persepsi Masyarakat," Magister Teknik Arsitektur Universitas Diponegoro, Semarang, 2008.

[13] J. DiMarzio, Beginning Android Programming with Android Studio, Indianapolis: John Wiley \& Sons, Inc, 2017.

[14] J. Raphael, "Android versions : A living history from 1.0 to 11," 22 Febuary 2020. [Online]. Available: https://www.computerworld.com/article/3235946/android -versions-a-living-history-from-1-0-to-today.html.

[15] P. M. G. K. Katharina Pentenrieder, "Analysis of Tracking Accuracy for Single-Camera," 2006. [Online]. Available: https://www.researchgate.net/profile/Peter_Meier6/public ation/251736130_Analysis_of_Tracking_Accuracy_for_ Single-Camera_Square-Marker-

Based_Tracking/links/544781000cf2f14fb811f89b.pdf. 


\section{BIODATA PENULIS}

\section{Rizki Azandika Erdiantama}

Lahir pada tanggal 02 Mei 1999 di
Jakarta. Seorang mahasiswa yang sedang
menempuh pendidikan seputar desain di
Politeknik Negeri Media Kreatif Jakarta.
E-mail : rizkiazandikae@gmail.com

